\title{
Knowledge and the Role of Institutions in Economic Theory
}

\section{Revised final draft}

\author{
(C) Lawrence A. Boland
}

\begin{abstract}
Though economic analysis and general reasoning are of wide application, yet every age and every country has its own problems; and every change in social conditions is likely to require a new development of economic doctrines.
\end{abstract}

Alfred Marshall [1920]

For more than six decades, neoclassical economics has been criticized for neglecting the social institutions that form the framework in which the neoclassical economy functions. In North America the criticisms have come from those economists who huddle under the banner of 'institutional economics' and focus on the problem of explaining institutional change. This paper discusses the role of institutions in neoclassical economics. Whether there is a problem with how neoclassical economics explains the evolution of institutions is a question open to debate. Proponents of neoclassical economics argue that since one can explain any institutional setting and its evolution as merely the consequences of the logic of choice (i.e. of optimization facing given constraints), our understanding of institutions is merely another example of neoclassical analysis (e.g. James Buchanan, Gordon Tullock and Douglass North).

The primary concern of some opponents of the neoclassical economics has been to show that the pro-neoclassical view is simply false. In particular, they have seen that advocates of the neoclassical view presume that neoclassical choice theory can easily be made dynamic. Some opponents go so far as to argue explicitly that this presumption is completely unfounded [Shackle 1972; Hicks 1976]. The question of dynamics is even sometimes alleged to be the 'fatal flaw' of neoclassical theory [Robinson 1974].

So much has been made of this criticism over the last two decades that those institutionalists among the anti-neoclassical group have turned their attention from a study of the nature of institutions to the study of the evolutionary aspects of any economy. So far, the institutionalists' critical programme of study - called 'evolutionary economics' - has failed to persuade neoclassical economists to drop their 'paradigm'. To the contrary, many neoclassical theorists believe that the evolution of an economy's institutional setting can be explained within the neoclassical paradigm [e.g. Buchanan and Tullock 1962]. However, it would be misleading to suggest that this is only a methodological dispute over the ability to 'explain within'. Underlying this question is a more fundamental theoretical issue concerning the nature and role of institutions in neoclassical theory.

Here I will argue that the essence of the methodological dispute lies not in the depths of sterile philosophy, but in the apparently contradictory roles played by institutions in economic theory. On one hand (viz. in neoclassical theory), institutions are tacit or given static constraints which ultimately define various equilibrium positions. On the other hand (viz. in economic policy analysis), institutions are explicitly dynamic or active instruments used either to facilitate or to prevent change. Both aspects of institutions are explicitly recognized in Lance Davis and Douglass North [1971]. Following Buchanan and Tullock, Davis and North distinguish between the institutional environment, which includes the 'legal ground rules' that constrain on-going political and economic business, and the institutional arrangement, which provides a workable mechanism either for operating within the ground rules or for changing them. It will be shown that any appearance of contradiction here can easily be overcome with an explicit recognition of the 
relationship between institutions and knowledge.

I will argue here that since the neoclassical conception of an institution (i.e. a short-run constraint) is inherently static, all attempts to promote and defend the pro-neoclassical view will necessarily result in methodological failures. Moreover, if neoclassical economics is ever going to be able to explain the evolution of institutions then a broader view of institutions will have to be developed. I think such a broader view is possible within neoclassical economics. But, unless the dynamic nature of institutions is properly explained, no explanation (neoclassical or institutional) of evolutionary economics can ever succeed.

I will begin by presenting the neoclassical view of institutions, namely, the one where institutions are merely some of the constraints facing the optimizer. Specific attention will again be given to the Marshallian method of dealing with the dynamics of constraints. Next, I will summarize my criticism of the adequacy of any neoclassical programme for dealing with questions of dynamics. Then I will present a theory of the nature and role of institutions designed to overcome the inadequacy of the neoclassical approach to institutional dynamics. ${ }^{1}$ It will be based on an explicit recognition of the relevant epistemological questions involved as well as the instrumental aspects of institutions. Finally, I will explain the essential relationships among time, knowledge and institutions.

\section{THE NEOCLASSICAL VIEW OF INSTITUTIONS}

Within neoclassical theory, all endogenous variables are explained as the logical consequences of self-interested rational choice, whereby one's choice may be limited by the similarly motivated rational choices of others through any activity in the market. This form of rational choice involves maximization (or minimization) of some objective function while facing some given constraints. The nature of the constraints facing any individual's choice may or may not be explained as a matter of his or her past or irreversible decisions or those of other individuals. Those constraints which are not considered a matter of choice cannot be explained within neoclassical theory. Operative constraints which limit individuals' choices (e.g. anything which is naturally given or beyond control, such as the availability of resources, technology, and so forth) are by definition the exogenous variables of neoclassical theory. ${ }^{2}$ Also by definition, any fixed or exogenous variable can be seen to play a determining role (viz. in the determination of the values of the endogenous variables) only if changes in that variable necessarily result in changes in the endogenous variables. ${ }^{3}$

Neoclassical theory, of course, recognizes many exogenous variables, including institutional or socially determined constraints such as legal limits and property rights. The constraints facing any individual's choice include some 'endogenous givens' which are determined in concert with the rational choices of other individuals; for example, the givens of consumer theory include marketdetermined prices. In this sense, some of any individual's constraints are explained as the consequences of (the equilibrium or concert of) all individuals' choices. Moreover, any constraint the establishment of which requires the (implicit) participation of many individuals is in some sense an institution. For this reason, some economists might consider a system of all marketdetermined prices to be an institution whose function is to provide the decision-maker with a 'summary of information about the production possibilities, resource availabilities and preferences of all other decision-makers' [see Koopmans 1957, p. 53]. However, the view that a price system is a social institution is true (if at all) only in long-run equilibrium, the attainment of which may take an unrealistic amount of time. More important, it would be very misleading to focus on prices as the only institutional constraint. The tendency to do so persists because many neoclassical economists rely on the normative view that price should be the only institutional constraint. As a matter of positive economics, dealing with real-time phenomena - which must exist in the short run - there are other institutions which constrain individual choices (see Coase's theorem). 
Whether or not the existing institutions can be explained away by assuming there are no incentives to change them, because they are optimum, is the moot point discussed in this paper. Given any neoclassical model of the economy, if there are many exogenous variables involved in the explanation of one or more endogenous variables, then formally there are many possible causal explanations for observed changes in the endogenous variables. The explanations formally differ only to the extent to which changes in different exogenous variables are recognized as the causes.

In these terms one can identify many types of neoclassical explanations which are distinguishable in terms of the method used in each to deal with the multiplicity of 'causes'. At one extreme, we find the approach which follows Walras and William Stanley Jevons in being concerned only with the logical and mathematical adequacy of the neoclassical model. ${ }^{4}$ At the other extreme is Marshall's approach, which is the foundation for virtually all neoclassical theories of institutions.

When there are many possible causes, (causal) explanation becomes a very difficult methodological problem. Solving this problem was the central purpose of Marshall's Principles of Economics. His solution was based on an explicit recognition of 'the element of Time' and its relationship with what he called the Principle of Continuity. As I explained before, the latter presumes that anything that can be varied in the given amount of time must yield to the Principle of Substitution, that is, can be explained as a matter of optimizing choice. His solution is built on two assumptions. First, he assumes away changes in all variables which are impossible to control (such as weather) or for which there is not enough time to change them (such as cultural traditions). Such variables cannot be explained with his Principle of Substitution hence they are unexplained givens or exogenous variables. Note again, such 'exogeneity' may depend on the amount of time under consideration. The second assumption is that it is possible to rank-order the changeability of variables such that those that can be changed more quickly are explained before those that are more rigid. Specifically, Marshall's method of duration-ordered periods depends on an assumption about dynamics, namely, about the rate at which the given variables could be expected to change. The rigidity of capital stock relative to the variability of labour is, of course, the hypothetical and only basis for the distinction between the long and short periods.

Although many variables are to be objects of choice in Marshall's long period, that period is not without some givens. He specifically noted that 'there are very gradual ... movements of longrun equilibrium prices caused by the gradual growth of knowledge, of population and of [available] capital, and the changing conditions of demand and supply' as well as changing social conditions 'from one generation to another' [Marshall 1920/49, p. 315]. There is nothing in Marshall's method which prevents any neoclassical economist from attempting to explain intergenerational changes in such variables as long-run prices or the long-run distribution of resources. ${ }^{5}$ But, if the changes in the long-run variables are to be explained as the results of changes in institutions (as elements of the 'social conditions'), the question is begged as to whether changes in the institutions are themselves the result of additional applications of Marshall's Principle of Substitution, that is, have the existing institutions been chosen in the way that other endogenous variables are chosen (as objects of optimization)? In other words, by including social conditions among the endogenous variables (i.e. among the objects of choice), neoclassical economists are merely modifying Marshall's concept of a long period without changing his neoclassical method. Whereas institutions (as 'social conditions') are among the exogenous givens in Marshall's long period, they are considered endogenous variables in the modified long-period analysis. In this manner, the modified long run forms the starting point for the neoclassical view of institutions.

In all neoclassical analyses of endogenous institutions, the prevailing institutional constraints are viewed as the outcomes of attempts to minimize costs or maximize benefits for those individuals or groups who are in a position to alter the institutions in the modified long run. Once the institutional arrangement (or environment) has been established, it becomes the set of ruling constraints on individual choices - at least in the short run. In terms of the logic of choice,

\section{(C) Lawrence A. Boland}


institutions are like capital, which by definition is fixed in the short run and is the basis of the cost functions facing the decision-maker. In the modified long run, when equilibrium has been reached, the optimum institutional constraints as well as the optimum amount of capital must have been chosen. The ultimate modified long-run equilibrium values of all endogenous variables, including the institutional constraints, are logically determined (for any given set of behavioural assumptions) by the values of the recognized exogenous variables that cannot be considered the results of optimization (either because they are difficult to change or their changes are beyond control). ${ }^{6}$

As implied early in Marshall's book, every explanation requires the recognition of something exogenous [1920/49, Book I, Chapter 3]. Since Marshall's long-run explanation (of prices) assumes that institutions (as 'social conditions') are exogenously given, any approach which makes them endogenous requires the recognition of something else as an exogenous variable. For example, the primary exogenous variable in Douglass North's neoclassical theory of institutional change is what he calls 'ideology'. In particular, the evolution of institutions is to be explained as the result of 'a fundamental change in ideological perspective' [1978, p. 974]. North adds that he sees 'no way to account for this transformation without the systematic study of the sociology of knowledge' [p. 974]. Although I can agree with this courageous statement, it would create methodological problems for the pro-neoclassical view, to which I now turn.

\section{A CRITIQUE OF NEOCLASSICAL THEORIES OF INSTITUTIONAL CHANGE}

Marshall cannot be blamed for the more recent tendency among neoclassical economists to take institutions for granted. In his theory of market prices, he did allow for the role of changing social conditions (including institutions) in the explanation of the history of an economy, that is, of the inter-generational changes of long-run prices and allocations. However, it must be recognized that to explain the dynamics of prices or allocations, one must explain why the social conditions have changed. This is because when changes in social conditions are considered exogenous (as in the Marshallian long run), they are thereby deemed unexplainable within the economic model. However, if the only reason the long-run endogenous variables (such as long-run prices) change is because social conditions changed, then the changes in the long-run endogenous variables remain unexplained. $^{7}$ It would seem, then, that for an adequate explanation of long-run prices, the evolution of institutional constraints (on short-run optimization) must be explained. In other words, the recent concern for institutions among neoclassical economists is not merely idle curiosity (nor more neoclassical 'imperialism'). It is a fundamental methodological requirement for a complete explanation of the dynamics of long-run prices and allocations.

There are two methodological aspects of neoclassical theories of the evolution of institutions which deserve critical examination. ${ }^{8}$ First, every neoclassical explanation presumes that (subject to constraints) individuals always get what they want, that is, all individual decision-makers are successful. As North observes, 'Neoclassical theory simply ignores the losers.' Although the presumption of successful decision-making may seem plausible in most neoclassical analyses, it should be recognized that it implies that the individual decision-maker's knowledge is always correct (or otherwise, how the required true knowledge was acquired must be explained as well [see Hayek 1937]). Since there is no inductive logic, there is no way to guarantee that the knowledge which is essential for successful decision-making is always true. Moreover, an induction-based knowledge involves a very static (since it is timeless) concept of knowledge, one which begs the question as to why there should ever be a change in long-run variables. This methodological problem can be overcome by explicitly recognizing the role of the decisionmaker's knowledge and by recognizing that changes are usually the result of systematic failures due to reliance on false knowledge, rather than of systematic successes based on necessarily true knowledge. 
Second, if the ultimate basis for any explanation of the changes of the institutional constraints is outside the neoclassical explanation, then the pro-neoclassical view cannot be sustained. As noted before, to avoid circularity every explanation of any set of variables requires the recognition of one or more exogenous variables. It should be obvious, then, that without a change in at least one exogenous variable (e.g. in an ideological perspective in North's theory), the long-run neoclassical economy is static, since there is no reason for a change in the endogenous variables (such as institutional constraints) once the optimum values of the institutional 'constraints' have been successfully established. If, for example, the optimizing changes in the endogenous constraint variables are to be explained as the result of changes in the exogenous ideology variable, then by definition of 'exogenous' (not explained within), that change in ideology must be explained outside the neoclassical explanation of institutions - an exogenous ideology cannot be an object of optimizing choice. But even worse, if one wishes to make ideology an endogenous variable in a neoclassical model, then another new exogenous variable must be invented. Of course, having to invent a stream of new exogenous variables as the neoclassical programme progresses merely means that one is marching down the long road of the infinite regress.

These methodological considerations reveal, I think, the inherent poverty of every neoclassical programme for explaining the evolution of the organizational structure (institutions) of an economy as the dynamic consequences of constrained optimization. Specifically, these considerations call into question the adequacy of the decision-maker's knowledge by questioning the presumed success of the intended optimization. They also question the neoclassical view of the nature of institutions which, for methodological reasons, views them as static constraints facing the short-run optimizer.

\section{A SIMPLE THEORY OF SOCIAL INSTITUTIONS}

Although I can agree with the view of North and others that the evolution of institutions can be explained, I cannot agree that a neoclassical programme by itself is methodologically sufficient. An adequate explanation of dynamics must recognize all limitations on successful decisionmaking as well as the essential role of knowledge. More important, an adequate explanation of the evolution of institutions must be based on a theory which explicitly gives institutions a broader role than is allowed by seeing them as merely static constraints on the choices of any individual decision-maker. I will outline a theory of institutions which will form a basis for an adequate explanation of institutional dynamics. Although my theory will not necessitate giving up the fundamental assumption of rational decision-making, it will show that all neoclassical theories of institutional change are very special cases.

To begin, I would like to note that the critical issues of the adequacy of the knowledge available to a decision-maker and the methodological role of institutions are not independent. The reason is simple. One of the roles that institutions play is to create knowledge and information for the individual decision-maker. In particular, institutions provide social knowledge which may be needed for interaction with other individual decision-makers. ${ }^{9}$ Thus, the following theory of institutions emphasizes the primary role of social institutions, namely, to institutionalize social knowledge. However, for an adequate dynamic theory, I will avoid the presumption of successful decision-making; thus, in particular, I will not assume that the social knowledge is correct, even though it may be durable. But I go too fast. Let me proceed very deliberately by putting my theory in the form of explicit propositions.

Proposition 1. All sociological acts are based on expectations of expectations. Specifically, all interactive decision-making involves the actor's knowledge of the other individuals' knowledge. ${ }^{10}$

The significance of this proposition lies primarily in the conceivable alternatives, such as the actor's direct questioning of the other individuals. ${ }^{11}$ 
Proposition 2. All social problems result from conflicts over expectations (or knowledge), which in turn result from the lack of acceptable limits on the range of expectations (at either source).

The significance of this proposition is dependent on the first and would mean little without it. Since most of our everyday experience involves previously solved social problems, it would be fairly difficult to give a pure description of any social problem apart from its assumed solution. Thus, I turn directly to solved social problems.

It should be clear that, based on the second proposition, all solutions to social problems involve the limits on expectations. There are basically two different ways of limiting expectations: (1) narrowing the range of possible options (with prohibitions, taboos, and so forth), and (2) increasing the likelihood of particular possible options (with norms, standards, guides, conventions, and so forth). This brings me to my third, fourth and fifth propositions.

Proposition 3. All social institutions exist to solve social problems.

Proposition 4. All social institutions can be divided into two categories: consensus institutions, which exist as socially accepted solutions to specific problems (or to a set of problems), and concrete institutions, which exist to solve social problems resulting from relying on consensus institutions (e.g. common agreements) to solve problems.

Proposition 5. All concrete institutions are attempts to manifest the extent of a society's learning, that is, they are a society's social knowledge.

And, as a corollary of the fifth proposition, I note:

Proposition 5a. The sole job of a concrete institution is to represent a given particular consensus institution (or system of institutions).

There are many examples of concrete institutions; the American Constitution is the most obvious, and legal contracts are the most common. Consensus institutions are much less obvious, but one can identify all 'unwritten laws' and 'gentlemen's agreements' as common examples. ${ }^{12}$

Propositions 1,2 and 3 form a static theory of institutions. That is, one can explain the existence of an institution by explaining the problem for which the institution was intended to be (or accepted as) a solution. ${ }^{13}$ Such problems include those discussed by North and others. One can also explain the continuance of the institutions by explaining the current problem for which the members of the society think the institution is a solution. In both cases the individual members may be mistaken, either in terms of the competence of the solution (as it may not do the job) or in terms of the realities of the problem (it may be a false problem or an impossible one to solve).

The addition of Propositions 4, 5 and 5a allows for a dynamic theory of institutions. More technically, these propositions form what has been called 'institutional individualism' [see Agassi 1975; Boland 1982a, Chapter 2]. If all institutions are considered to be essentially of the consensus type, it would lead to the view which Agassi called 'psychologistic individualism'. If all institutions were viewed as essentially concrete, it would lead to the view called 'institutional holism' (sometimes called 'collectivism'). ${ }^{14}$

The theory formed here views institutions as social conventions which can be influenced by individual members of the society but which also extend (in terms of time or space) beyond the individuals and thereby can influence the individuals either as constraints or as instruments of change. How the institutions can be influenced depends on the institutions designed to deal with that problem (such as election rules). This theory can best be understood in terms of a sequence of events or steps.

Step 1. A society faces a problem for which there is at least one conceivable solution.

Step 2. A consensus is formed around one particular solution, thereby establishing a consensus

\section{(C) Lawrence A. Boland}


institution.

The establishment of the consensus may depend on a political process. In the modern urban world, a consensus is virtually impossible to achieve. One can easily see that the institutions of political parties and platforms are parts of a solution to the problem of forming a consensus. Specifically, a platform ties together a set of problems for each of which a consensus for a particular solution cannot be obtained. To construct a consensus, every party member agrees to support all planks in the platform, even though he or she may not be interested in every plank.

Step 3. It is recognized that the solution of Step 2 has inherent methodological difficulties because a consensus institution is limited in terms of space and time.

In particular, the solution of Step 2 will be limited to the members that form the consensus in terms of both their life-span and their number. For example, in this semester's seminar, everyone may know what to expect of one another in terms of operating rules, but next semester (or in any other seminar at the same time) there will be a new set of students who may not know what to expect. Thus, every semester a new consensus will have to be reached. The fact that there is no carry-over from one period (or place) to another is in effect another social problem for which some form of durability is the only solution.

Step 4. The society establishes a concrete institution to represent the consensus of Step 2; however, the durability or concreteness of the institution is merely another consensus institution.

Durability is the essential ingredient for a truly dynamic model, even if the durability is not exogenous.

Step 5. In the future, the succeeding consensus is formed partly as a result of the existing concrete institutions and partly as a result of the existing social problems, and so forth.

In other words, when Step 4 has been reached, the succeeding generations are taught how to solve their social problems by teaching them about the existing (concrete) institutions. Of course, the process involves to a great extent teaching them what their problems 'are'. Note that concreteness may present other social problems, which in turn are solved by a higher level of concrete institutions (e.g. an ombudsman). Some societies may wish to prevent any further changes. Others may design their institutions so that they can be easily altered in order to be able to adapt to changing circumstances. Whether a concrete institution actually possesses the intended durability is an important question of dynamics, but the form of concreteness is still only a consensus institution. In other words, concrete institutions continue to exist only because we allow them to exist. As individuals, we can choose to ignore them or persuade others to ignore them. There may be certain social or personal costs involved in such a stance, but it clearly is an option open to every member of a society.

Clearly, with this theory the question of social change becomes very delicate because of the seemingly indeterminate nature of the structural relationship between problems and solutions at both static and dynamic levels. The structural relationship at issue is an instance of 'circular causation'. Simultaneously, in the process of teaching (or socializing) new members of a society, the prior existence of an institutionalized solution is used as evidence of the importance of certain social problems, but the existence of the solution is in turn justified on the basis of the prior existence of the social problem. Such a symbiotic relationship may lead to a very static society if the 'elders' are skilled at socializing. It also raises certain difficulties with regard to the concept of a change in 'social conditions', including the existing institutions. My presentation of a hypothetical sequence which would lead to a concrete institution presumed the existence of a consensus institution. But, given the symbiotic relationship, can the consensus institution be changed without a change in the concrete institution?

\section{(C) Lawrence A. Boland}


This methodological problem for the explanation of social change is usually avoided, but not solved, in one of two ways. The first way to avoid 'circular causation' is to view all concrete institutions (such as the laws that constrain individual choices) as the only real institutions. Although this view has the advantage of being clear-cut and more appealing to common sense, it also has the methodological disadvantage of leading its proponents to view all matters of social change as matters of only power politics. But more important, this view of institutions is inherently static. Once the institutions have been established, there can be no real institutional change, hence changes in other endogenous variables cannot be explained within the given institutional structure. This view's static nature, combined with its emphasis on power politics, leads its proponents to make political mistakes. For example, this view's proponents often oppose the establishment of an undesirable (concrete) institution because they fear the rigidity of its concreteness even though it can usually be shown that a concrete institution (such as a written rule) is easier to change than a consensus institution (an unwritten rule). ${ }^{15}$

The second way to avoid the problem of 'circular causation' is to say that consensus institutions (which underlie any concrete institutions) are the only real institutions. Moreover, there may be more than one way to represent a consensus institution; thus, changes in concrete institutions do not imply changes in consensus institutions or social conditions. This alternative has the advantage of avoiding collectivist dogma, but the disadvantage of viewing all social change entirely as a matter of persuasion (such as 'Madison Avenue' advertising techniques). Of course, with this view, changes in social conditions are very slow whenever communication is very controlled (e.g. 'one should not talk about such things'). But there is a more serious methodological problem. It is virtually impossible to know when a consensus institution has changed, and thus an operational explanation of social change becomes impossible. Any theory (such as Marshall's) which explains long-run changes in prices as the consequences of changes in social conditions (consensus institutions) is inherently untestable!

Neoclassical theories of institutional change can be seen to be variants of the theory represented by Propositions 1 through 5a. But being basically concerned with the individual decision-maker, every neoclassical theory would have to view real changes as those in consensus institutions; however, such changes may (have to) be brought about by changes in concrete institutions. It should be clear that most modern societies provide specific institutions which make orderly changes or the creation of other institutions possible. The legislative bodies of most Western democracies are an example. In fact, the changeability of any institution is a problem for which the rigidity of other institutions provides the solution. It should be noted that those institutions whose role is to provide information (such as norms, guidelines and legal limits) are effective only to the extent that they are stable. Thus, the changeability of such institutions compromises their knowledge role [see further, Newman 1976].

The critical issue with any neoclassical variant, as noted earlier, is whether a chosen concrete institution is, in fact, a successful representation of a given consensus institution (e.g. whether it adequately represents the given ideology). Kenneth Arrow's (im)possibility theorem [1951/63] might easily be seen as an argument against the possibility of (complete) success in every social situation. Specifically, one cannot guarantee a successful social decision mechanism (a concrete institution) which will always represent the society's welfare function (a consensus institution).

Similarly, there is the critical issue of the adequacy of the solution over which the consensus is formed. Does the given ideology, for example, solve the social problems that exist? People may think the market system can solve all social problems, but that does not prove that it can. It is only a conjecture, the truth of which is neither proven nor provable. For example, Arrow [1974] has argued that one essential ingredient for social interaction (which includes doing business in the market as well as within the firm) is simple trust but the existence of a market for trust would be a virtual contradiction. 


\section{TIME, KNOWLEDGE AND SUCCESSFUL INSTITUTIONS}

The neoclassical programme for explaining the evolution of an economy's institutions is quite compatible with my simple theory of the epistemological role of institutions. However, once one recognizes that neoclassical programmes (Marshallian or otherwise) presume successful decisionmaking and hence, for continuing success over time, that every individual must possess correct knowledge (which includes accurate representations of relevant consensus institutions), it becomes clear that a neoclassical theory is a special case of my version of institutionalism presented here. That is, in my theory, when the consensus institutions do succeed in accurately representing those solutions, then (and only then) are my theory and a neoclassical theory of institutional change completely compatible.

Neoclassical theories are incompatible with my theory whenever any individual's knowledge is not correct (i.e. not true). But, incompatibility is not the important issue here. As has been argued elsewhere [e.g. Hayek 1937; Hicks 1976], the existence of false knowledge is an essential ingredient in any dynamic theory of economic decision-making. If all knowledge were true (including knowledge about the future), then there would be no reason for (disequilibrium) change without changes in one or more exogenous givens. If one is going to explain change, the source of the change cannot be exogenous. Thus, it has been argued, dynamic theories must recognize false knowledge (and explain why it might be false). Furthermore, a theory of dynamic behaviour must specify the systematic way each individual responds to the discovery that his or her knowledge is false. Stochastic theories, their popularity notwithstanding, do not explain response variations but only cover up the failure systematically to explain them accurately. ${ }^{16}$

In this paper I have extended this dynamic issue of false knowledge to the question of institutions. I have argued that institutions provide essential knowledge to individual decisionmakers. If that institutional knowledge is false, there is another reason for change. The only difference between institutional knowledge and knowledge in general is that the former (like capital) takes longer to change. In other words, institutional knowledge may be durable, and its durability may create problems. Even though an institution may successfully represent social knowledge that is true for one period of time, its durability may extend to a period for which it is false. Thus, since institutional knowledge is durable, it is likely to be false. Moreover, the existence of false institutional knowledge is a reason for change and, because change takes time, false knowledge is a continuing reason why the success assumption of neoclassical explanations is often unrealistic.

Douglass North's ultimate argument in favor of the pro-neoclassical view is that to "abandon neoclassical theory is to abandon economics as a science." [1978, p. 974] This pitifully weak argument is rather misplaced, even though it is the same excuse given by Marshall [1920/47, p. $379 n]$. Those of us who argue for the recognition of false knowledge and inadequate institutions do so not because we think (as North fears) that neoclassical theory should be abandoned, but because we think neoclassical analysis should be kept in perspective, that is, it should be recognized as a very special case.

\section{NOTES}

1 This theory of institutions was developed in an undergraduate sociology class that I taught in 1968.

2 Exogeneity is, of course, defined as the purported intrinsic property of certain variables of a model within which they cannot be explained (i.e. they are not influenced by changes in endogenous or other exogenous variables of the model).

3 For a more detailed discussion of the methodological role of exogeneity and the requirements of determinant explanations, see Boland [1975].

4 Consequently, in terms of the logic of solvability, it does not matter whether a formal constraint is socially given or is a parameter of nature (e.g. available resources).

5 To avoid circularity, it must be remembered that there still have to be some givens which do not 
endogenously change within or with the generation.

6 For the given values of the exogenous variables, if the current choices of values for the endogenous variables are such that there exist incentives for changes in any endogenous variables, then the (modified) long-run equilibrium has not been reached.

7 For more on the methodological question of explaining dynamics, see Boland [1978] and for a discussion of the technical requirements of explanation as distinguished from description, see Boland [1975].

8 I say 'methodological aspects' to distinguish them from empirical aspects, such as the truth of the assumptions about the relative variability of the givens used to distinguish the short run from the long run.

9 The equilibrium price system is one instance of such a social institution; other institutions include the laws governing trade and advertising practices and tax laws. The extent to which the social knowledge provided (such as norms, guidelines and legal limits) is necessary is directly related to the power of the institution.

10 Such a situation was recognized by Plato in his dialogue 'Laches'. It is observed at the beginning that 'some laugh at the very notion of consulting others, and when they are asked will not say what they think. They guess at the wishes of the person who asks them, and answer according to his, and not according to their own, opinion.'

11 Clearly, it does not attempt to be relevant for the explanation of the observed behaviour of a hermit or anyone else who opts out of a society (although it would apply to a group that opts out). In other words, it does not attempt to apply to an asocial situation.

12 In correspondence, Ludwig Lachmann noted to me that he offered a similar theory of social institutions in his 1970 book. His illustration of the differences between consensus and concrete institutions is the difference between 'the market' and the stock exchange.

13 Of course, not all solutions are invented or designed - some may be 'discovered'.

14 Let me define these two different views of the explanatory relationship between institutions and individuals. Psychologistic individualism is the methodological requirement that says all explanations of institutions must recognize that only individuals can make decisions and that the only exogenous variables allowed are nature-given, including the psychological states of the decision-makers. Institutional holism would allow other exogenous variables such as the 'destiny of the nation', class interest, etc. In the extreme, institutional holism would deny a role for the individual in determining the social outcomes [e.g. Sraffa 1960].

It is commonly thought that if an explanation is not psychologistic-individualist then it is 'holist' (or 'collectivist'). This is a mistake. The distinctions to be drawn are between individualism and holism and between psychologism and institutionalism. This means that there are four distinct views. Economists since Schumpeter use the term 'methodological individualism' to actually mean the stronger psychologistic individualism. It would be best to reserve the term 'institutional individualism' to indicate the form of individualism that allows exogenous variables beyond the limits of natural givens and psychological states of the individual.

15 Similarly, when in power, this view's proponents waste much time or many resources on superficial changes, that is, on those which change (concrete) appearances without altering the underlying consensus.

16 For a more elaborate discussion of the methodological problems with stochasticism in economic models, see Boland [1982a, Chapter 7; 1989, Chapters 1, 7 and 8].

\section{References}

Agassi, J. [1975] 'Institutional individualism' British Journal of Sociology 26, 144-55

Arrow, K. [1951/63] Social Choice and Individual Values (New York: John Wiley)

Arrow, K. [1974] The Limits of Organization (New York: Norton)

Boland, Lawrence A. and Geoffrey Newman, (1979) 'On the Role of Knowledge in Economic Theory,' Australian Economics Papers 18 71-80.

Boland, Lawrence A., (1979)'A Critique of Friedman's Critics,' Journal of Economic Literature 17 500-19

Boland, Lawrence A., (1978) 'Time in Economics vs. Economics in Time: The 'Hayek Problem,' Canadian Journal of Economics 11 240-62

\section{(C) Lawrence A. Boland}


Boland, Lawrence A., (1975)'Uninformative Economic Models,' Atlantic Economic Journal 3: 27-32.

Buchanan, James M. and Gordon Tullock, (1962) The Calculus of Consent (Ann Arbor: University of Michigan Press).

Davis, Lance E. and Douglass C. North, (1971) Institutional Change and American Economic G rowth (Cambridge: the University Press).

Hayek, Friedrich, (1937) 'Economics and Knowledge,' Economica 4 N.S. 33-54.

Hicks, John R., (1976) 'Some Questions of Time in Economics,' in Evolution, Welfare and Time in Economics, edited by Anthony M. Tang, Fred M. Westfield, and James S. Worley (Toronto: D.C. Heath,), pp. 135-51.

Koopmans, Tjalling C., (1957) Three Essays on the State of Economic Science [New York: McGraw-Hill,], p. 53).

Lachmann, Ludwig, (1970) Legacy of Max Weber (London: Heinemann,)

Marshall, Alfred, (1920/49) Principles of Economics, 8th ed. (London: Macmillan,),.

Newman, G. [1976] 'An institutional perspective on information' International Social Science Journal 28, 466-92

North, Douglass C., (1978): 'Structure and Performance: The Task of Economic History,' Journal of Economic Literature 16 963-78.

Robinson, Joan, (1974) 'History versus Equilibrium,' Thames Papers in Political Economy

Shackle, G.L.S., (1972) Epistemics and Economics (Cambridge: the University Press,)

Sraffa, P. (1960) Production of Commodities by means of Commodities 